\title{
Value Encounters - Modeling and Analyzing Co-creation of Value
}

\author{
Hans Weigand \\ Tilburg University, Dept. Information Systems and Management, P.O. Box 90153, \\ 5000 LE Tilburg, The Netherlands \\ H.Weigand@uvt.nl
}

\begin{abstract}
Recent marketing and management literature has introduced the concept of co-creation of value. Current value modeling approaches such as e3-value focus on the exchange of value rather than co-creation. In this paper, an extension to e3-value is proposed in the form of a "value encounter". Value encounters are defined as interaction spaces where a group of actors meet and derive value by each one bringing in some of its own resources. They can be analyzed from multiple strategic perspectives, including knowledge management, social network management and operational management. Value encounter modeling can be instrumental in the context of service analysis and design.
\end{abstract}

Keywords: Service-Dominant logic, value modeling, business ontology.

\section{Introduction}

In recent years, Vargo and colleagues $[27,16,1]$ have contributed to the development of service science [23] by introducing the concept of "service-dominant (S-D) logic". As the name suggests, S-D logic focuses on service provision in contrast to goods production (G-D logic). S-D logic can be seen as an attempt to view services not as a particular kind of (intangible) good that should be produced and marketed in the same way as traditional goods. Service provisioning is doing something before and with another party. In this perspective, what the company provides is not an output, but an input for a continuing value-creation process. The shift from G-D to S-D logic is one from a value proposition consisting of operand (passive) resources to one consisting of operant (active) resources. Instead of seeing value being created within companies that exchange the means for this value creation from one to another, it sees the value being created between companies (or companies and consumers). In its focus on cocreation of value, it builds forth on already existing management theory work of Norman [18] and Prahalad [21] and the marketing literature [12]. The notion of S-D logic still needs to be worked out further and gain more empirical validation [5], but in this article, we take it as a starting-point, and address the question how to support this logic using current value modeling and business ontology approaches [3].

Current value modeling approaches can deal well with services and have provided several conceptual tools to support service design [15, 30, 13]. However, they fall short at the moment in supporting an S-D analysis of value creation. In particular, when focusing on e3-value (see section 2), we note the following limitations: 
- To assess the sustainable value of network collaboration, the analysis must look beyond economic transactions. The dynamics of intangible benefits, in particular the effects on knowledge development and the social network, need to be taken into account as well.

- Collaborations often involve more than two actors. Although an e3-value analysis helps to clarify the value that each actor draws from other parties in terms of value that they receive, the model does not identify the value that the stakeholders draw from the collaboration as such. The same holds for the resources that they bring in. The e3-value model breaks up the collaboration into binary value exchanges. This approach is fitting from a purely economic perspective, as contracts are most often made between two parties, but it can obstruct a holistic understanding of the collaboration and the value that is created in the collaboration.

In order to overcome these limitations, this paper introduces an extension of the e3value approach in which collaborations are treated as first-class citizens. To assess the viability and sustainability of the collaboration, we take a holistic approach. We introduce the notion of value encounters in which the collaboration becomes concrete. The validity of this construct is put to the test in two ways: first, by a fictive but realistic business scenario from the health care domain that we model (section 4) and analyze (section 5). Secondly, by developing a formal ontology of the value encounter (section 6). In section 7, we draw some conclusions and relate to other work in business economics.

\section{Background: Value Modeling}

There exist a number of approaches, languages, and ontologies for business modeling in literature. In [3] the e3-value [9] and the REA ontologies [17] were compared (together with a third business ontology - the BMO [Os04]) in order to establish a common reference business ontology. One result of that comparison was a set of mappings between e3-value and REA indicating strong similarities between the concepts of the two. Both REA and e3-value were originally designed for capturing tangible exchanges of economic resources between actors. Allee [2] complements this view by proposing to include intangible exchanges as well. Examples of resources transferred through intangible exchanges are knowledge or status.

The Resource-Event-Agent (REA) ontology was formulated originally in [17] and has been developed further, e.g. in [8] and [26]. REA was originally intended as a basis for accounting information systems and focused on representing increases and decreases of value in an organization. REA has been extended to form a foundation for enterprise information systems architectures [14], and it has also been applied to e-commerce frameworks [26]. The core concepts in the REA ontology are Resource, Event, and Agent. The intuition behind the ontology is that every business transaction can be described as an event where two actors exchange resources. To acquire a resource an agent has to give up some other resource. For example, in a goods purchase a buying agent has to give up money in order to receive some goods. The amount of money available to the agent is decreased, while the amount of goods is increased. Conceptually, two events are taking place: one where the amount of money is decreased and another where the amount of goods is increased. This combination of events is called a duality and is 
an expression of economic reciprocity - an event increasing some resource is always accompanied by an event decreasing another resource. A corresponding change of availability of resources takes place at the seller's side. Here the amount of money is increased while the amount of goods is decreased.

There are two types of events: exchanges and conversions [14]. An exchange occurs when an agent receives economic resources from another agent and gives resources back to that agent. A conversion occurs when an agent consumes resources to produce other resources. Events often occur as consequences of existing obligations of an actor; in other words, events fulfill the commitments of actors.
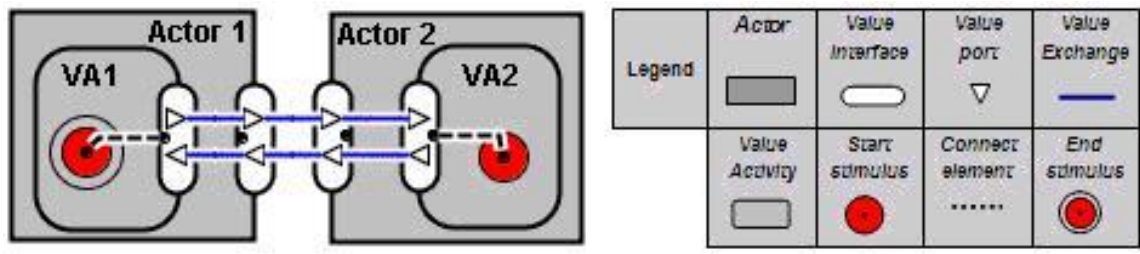

Fig. 1. Basic e3-value constructs

The e3-value value ontology [9] aims at identifying exchanges of resources between actors in a business case. It also supports profitability analyses of business cases. The ontology was designed to contain a minimal set of concepts and relations to make it easy to grasp for its intended users. e3-value includes a graphical notation for business models. The basic concepts in e3-value are actors, resources, value ports, value interfaces, value activities and value transfers (see Fig. 1).

An actor is an economically independent entity. An actor is often, but not necessarily, a legal entity, such as an enterprise or end-consumer or even a software agent. A set of actors can be grouped into a market segment. A resource (also called value object) is something that is of economic value for at least one actor, e.g., a car, Internet access, or a stream of music. A value port is used by an actor to provide or receive resources to or from other actors. A value port has a direction: in (e.g., receive goods) or out (e.g., make a payment), indicating whether a resource flows in to or out from the actor. A value interface consists of in and out ports that belong to the same actor. Value interfaces are used to model economic reciprocity and bundling. A value exchange represents one or more potential trades of resources between these value ports. A value activity is an operation that can be carried out in an economically profitable way for at least one actor.

According to Allee's approach to value network modeling [2], a distinction must be made between tangible and intangible exchanges of resources. Tangible exchanges are established and explicitly regulated in contracts. They correspond to exchanges of economic resources in the REA ontology and e3-value. Intangible exchanges are established informally and their terms are not present in contracts. As stated in [2], "Intangible knowledge and information exchanges flow around and support the core product and service value chain, but are not contractual. Intangibles include those "little extras" people do that help keep things running smoothly and build relationships. These include exchanges of strategic information, planning knowledge, process knowledge, technical 
know-how, collaborative design work, joint planning activities, and policy development." There is no formal correspondence between an intangible exchange and any concept in REA or traditional e3-value.

E3-services [15] is an extension of e3-value that is aimed at identifying bundles of services. E3-services introduces the concepts of needs, consequences and wants. The consequence of a service is anything that results from consuming valuable service properties. A need is a solution-independent goal, whereas a want is defined as a service implementing a specific solution. A want matches a need when the consequences of the want satisfy the need. Consequences are viewed in a broad sense. Both functional properties and quality properties are taken into account. For the purpose of this paper, e3-services is interesting for two reasons. First, because it adopts a broad perspective on the notion of service value as described in terms of consequences. Secondly, because it goes beyond the description of a value object being exchanged and provides instruments to describe a proposed service as well as a required service and how these two are matched. However, we note that the conceptualization of "needs" and "wants" betters matches with G-D logic than with S-D logic that prefers to talk about enabling rather than relieving a need.

\section{Motivating Example}

For illustrative purposes and as a running example we use the fictive but realistic business scenario from the health care domain, including actors such as hospitals, patients, and medical equipment providers, as described in [4]. It is constructed to highlight some problems related to exchanges of resources that a business analyst or modeler may encounter. The verbal description as given below is intentionally underspecified and imprecise, as this is always the case in practice. Therefore, it should be analyzed, for instance, using the value object analysis introduced in [28].

The Hospital purchases medical equipment from the Medical equipment providers by placing Orders and paying Cash. Furthermore, the Hospital acquires Product knowledge through their interactions with the Medical equipment providers.

The Sales agents assist the Medical equipment providers to acquire new customers, i.e. they market the products of the Medical equipment providers, negotiate with potential customers and deliver valid Customer orders to the providers. Through participating in this interaction, the Sales agents will get Product knowledge from the providers, while the latter will get Market knowledge from the Sales agents.

The Patients receive Health care services from the Hospitals such as examinations and treatments. These services will improve the Health state of Patients but also their Knowledge about their health conditions as well as their Feeling of safety. The Hospitals will get paid by the Insurance Company of the Patient. They also get improved Medical knowledge by examining and treating complex cases. The Government collects tax from citizens in order to provide health care for all. The Hospitals interact with the Government providing Health care services and receiving Cash in return. Furthermore, the Government gives the Hospitals access to the market by providing Authorization. The Hospitals may participate in Professional communities with which they exchange Knowledge. A Professional community will also get the Attention of the Hospital. Through its participation the Hospital will earn Status. 


\section{Value Encounter Modeling}

When addressing a certain value network, the value encounter analysis postpones the question of who is exchanging value to whom, but focuses on the value encounters first. A value encounter is an interaction space between multiple actors where each actor brings in certain resources; these resources are combined then in such a way that value is created to all of them. Value encounters can be connected by means of a causal relationship ("+"), when activity in one encounter reinforces the activity in another encounter. In this way, the dynamics of the system become apparent.

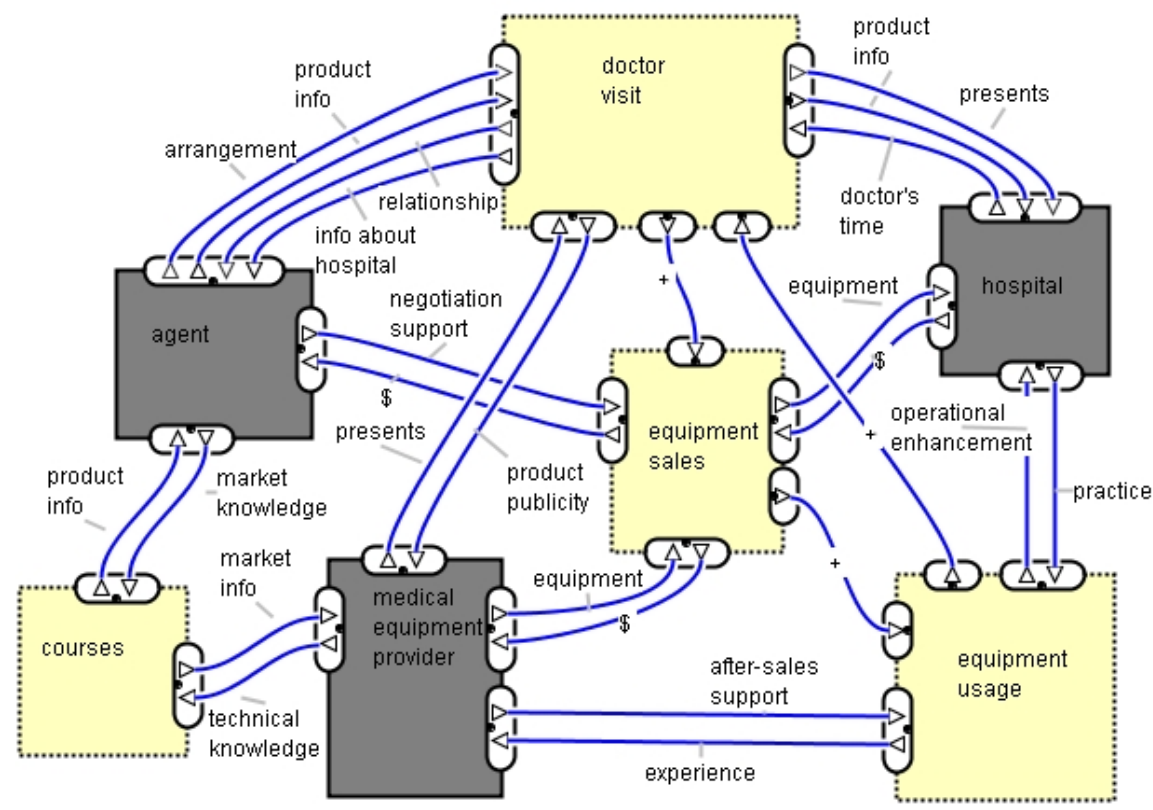

Fig. 2. Value encounters medical equipment agent

In the hospital example, several independent groups of value encounters can be distinguished:

- Between Hospital, Equipment Provider and Agent having to do with the purchasing of medical equipment.

- Between Hospital and other Hospitals, having to do with knowledge sharing and legitimization.

- Between Hospital, Patient and Insurance Company having to do with health care provisioning.

- Between Hospital and Government (not worked out in this paper)

We start with the first group, depicted in Fig. 2. The value encounters are rendered graphically as dotted light (yellow) rectangles. We have distinguished four encounters. 
Each of them creates certain value independently of the other, but they mutually reinforce each other, so they are put together in one group. The doctor visit is an encounter. This is an interaction that does not involve an economic transaction and hence would not be included in a traditional e3-value model. Nevertheless, it is of crucial importance for the business model of the Agent, and has also value for the other actors. For the Agent, the primary goal is to build a relationship with doctors and be kept informed about possible needs of the hospital. For the doctor, the value is that he receives information about new products and possibly also some give-away from the Provider. However, it does cost him some time investment. For the Provider, the value of the interaction is in the publicity that he gets.

The second value encounter contains an economic transaction, the purchasing of a piece of equipment. Variants would be possible as well, for instance that that the equipment is leased. Presumably, the Agent contributes to the value encounter by active support in the negotiation and administration. In return, he receives a certain fee. Note that a situation like this in which three parties are involved cannot be rendered straight-away in traditional e3-value; the encounter would be split up in two transactions, one between Provider and Hospital (the equipment) and one between Provider and Agent (negotiation service). That these two value transactions are intrinsically intertwined cannot be expressed.

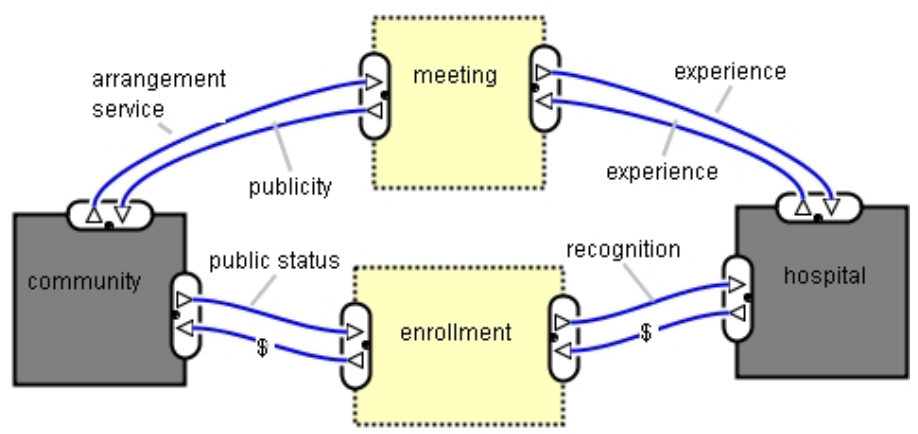

Fig. 3. Value encounters hospital community

The third value encounter is about the actual usage of the equipment. Here the Provider brings in technical support and perhaps spare parts. The Hospital gains operational enhancement (support for its medical work). However, the usage of the equipment also brings in practical experience from which the Provider can gain.

The fourth encounter is between Provider and Agent only, and involves an exchange of knowledge, e.g. in the form of a course. The Provider brings in his technical expertise, from which the Agent gains product knowledge.

The second group of value encounters (Fig. 3) concerns the participation of the hospital in the professional community. The bottom line would be that hospitals interact in a peer-to-peer fashion. However, on the basis of the description we assume that there is an institutionalized community that facilitates these interactions.

A distinction is made here between two encounters: the first creates and maintains enrollment. From this encounter, the hospital can claim recognition. The resource that 
the community brings in is nothing more or less than its public status. The second value encounter consists of the meetings organized by the community in order to facilitate the sharing of experience. Evidently, there are typically more supporting actors involved, like catering, or could be involved, such as equipment providers sponsoring the meeting in return for some publicity. The goal of the value model is to express what is deemed relevant at some point in time, not to be complete.

The third value encounter group (Fig. 4) is about the health care itself.

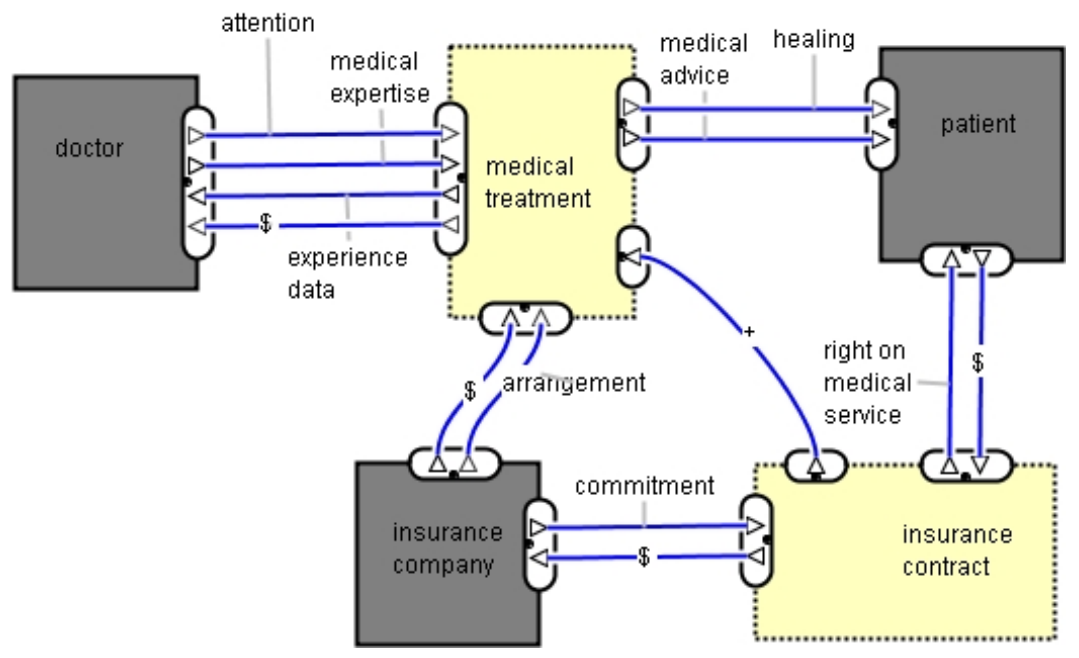

Fig. 4. Value encounters doctor-patient

The medical treatment is modeled here as a single value encounter. This is a simplification of course, as many different kinds of encounters - doctor visit, surgery, hospital care, etc. - could be distinguished. Basically, the Patient receives medical advice and healing. The Doctor brings in his medical expertise and his attention. On the other hand, he gains experience data from the encounter itself. The Insurance Company is paying the treatment and is therefore a stakeholder as well. In certain cases, the Insurance Company is the one that can arrange a medical treatment for its customers, so we have included this service as well. The value encounter between Insurance Company and Patient is about the contract. The patient pays for a right on medical service in return. The company brings in a commitment (we will guarantee your medical care). There is a relationship identified between the value encounters: the more contracts the insurance company has acquired, the more medical treatments it has to arrange.

\section{Value Encounter Analysis}

Once the value encounters have been modeled, the next step is to analyze them. Analysis always focuses on one aspect at a time. Which aspects are relevant differs from case to case. Complementing the profitability analysis provided by traditional e3-value, we propose the following: 
- value activity analysis

- knowledge management

- social network (social capital) management

- operational management

Although profitability analysis is not worked out here, it should be noted that starting from value encounters, profitability analysis and contract design need to be performed in combination. A value encounter model does not show how the money is distributed exactly, which is needed for the profitability analysis. This depends on the way the multiparty collaboration is broken up into bilateral contracts. Fairness is an important variable in sustainable value networks that should play an important role in this breaking up.

Value activity analysis. The initial value encounter model depicts value encounters as black boxes. In order to get a better understanding of how value is created, we can identify the value activities that happen within the value encounter. These value activities are connected to the value encounter inputs and outputs. In simple value transfers, the value activity is low profile and input is almost equal to output. In general, there is not always a 1-1 relationship between inputs and outputs. For example, consider the value activity analysis of the Hospital-Patient encounter (Fig. 5).

We have distinguished an appointment activity and a payment activity, the latter being fed by the former. The experience that the Doctor gains from the encounter has no direct corresponding input as it is gained from the interaction itself. In contrast, the arrangement that is brought about by the Insurance Company has no direct corresponding output, as it is the interaction itself that profits from the arrangement.

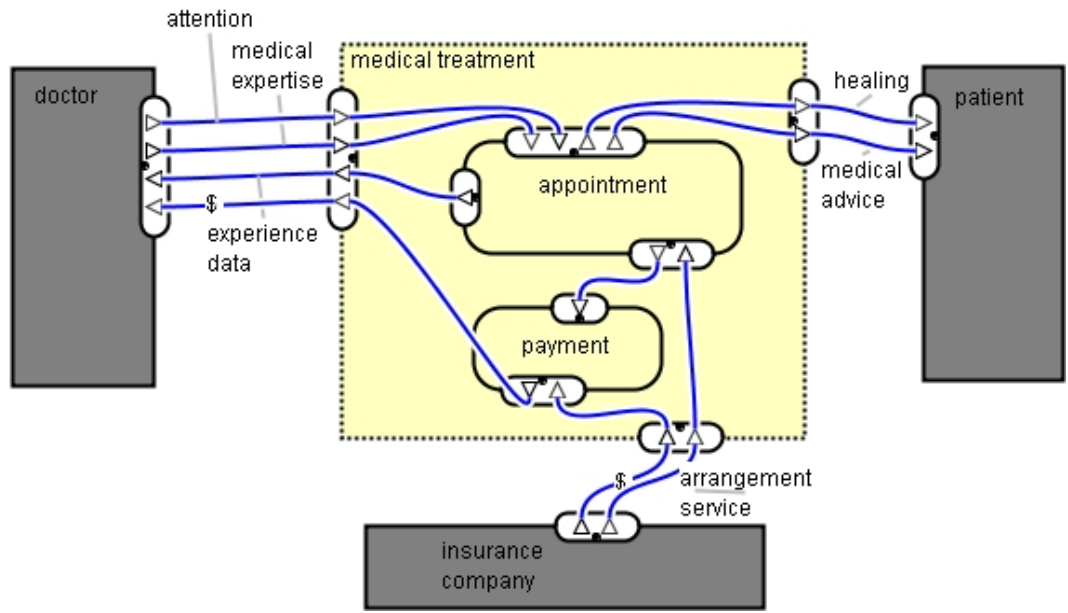

Fig. 5. Value activity analysis

Knowledge Management. From the KM perspective, the question is: how do actors maintain their knowledge resources [7, 2]? The assumption is that for actors to survive 
in the long run, their knowledge - both explicit and implicit in routines - is the core competency [6].

Some sub questions are:

- Is there a healthy mix of explicit and implicit knowledge transfers? In the case of the Hospital, we see in fact instances of both.

- If certain data is available, is it possible to gain more value from it, e.g. by Business Intelligence techniques? For example, the experience data that the doctor gets from patient consults. If some of these data are encoded digitally, the hospital could integrate the information from different sources and mine for certain patterns.

- Is the knowledge acquired also explored? For example, if medical equipment is to be purchased, are all doctors with relevant knowledge involved in the process?

- Is the knowledge making up core competencies actively maintained and increased? In the example, we see that the Hospital maintains its knowledge in various ways: from contacts with Agents, from dealing with Patients (complex cases) as well as from interaction with other Hospitals in the community.

Social network management. Over time, individual actors will change their value proposition. To enable evolution of the value network drawing on the same partner base, the social network underlying the collaboration should be kept healthy [16, 25]. So the main question here is: how do actors maintain their social network?

Some sub questions are:

- Is there a healthy mix of informal (face-to-face) and formal contact? In the example, most of the value encounters are based on face-to-face meetings in which social relationships are maintained in a natural way. However, more attention could be given to the formal part, e.g. by the use of evaluation forms regarding the doctor-patient encounter (on some regular basis).

- Is information about the social networks maintained in a systematic way? In the hospital case, this is particularly important for the Agents who are very much dependent on good relationships with the doctors. The hospital itself could consider the opportunity to integrate the multiple social networks that its doctors maintain individually. Although such integration is not something that can be imposed, it can be stimulated by providing facilities such as a professional social network platform.

- Is the social network actively explored? For example, the hospital can explore the social network it maintains within the community when job vacancies have to be filled.

- Is the social network actively developed? Actual participation in a hospital community and its meetings is a point in case.

Operational management. For a value encounter to be satisfactory in the long run, it must be run efficiently for all participants. Treacy and Wiersema [24] mention operational excellence as one of the three critical value disciplines. The question is: how to optimize the efficiency of the value encounter?

Some sub questions:

- How is the value encounter to be characterized? To answer this question, the analyst can make use of encounter patterns. Examples of patterns are "group meeting", "single service counter", "sequential service counter", "1-1 meeting" and "sales". 
In some cases, the pattern needs to be decided on carefully. For instance, is the doctor visit in the hospital organized as a single service counter (each doctor viewed independently) or a sequential one? The choice has consequences for the way the encounter is to be supported.

- How is the value encounter supported? Continuing the example from above: in the former case, a simple agenda planning system per doctor is sufficient. In the latter case, if the patient will have to visit several service points, one should try to minimize waiting time and a global planning system is needed. For value encounters characterized as "group meeting", a registration system is needed.

- How is the optimization of the encounter ensured? To optimize the efficiency of the value encounter, it needs to be monitored, and the responsibility of this task should be allocated. Different stakeholders in a value encounter will have different optimization goals, so there is a risk of Prisoner Dilemma phenomena. In some cases, there is a natural "leader" and the allocation is easy; e.g. when there is a binary collaboration between a provider and a customer segment. In complex cases, the monitoring can be allocated to a partner that is involved for this function. Or the parties can agree on collaborative monitoring.

\section{Value Encounter Ontology}

In the above, we have introduced the value encounter concept in an informal way. In order to apply the technique in a consistent way, we need a more formal definition as well.

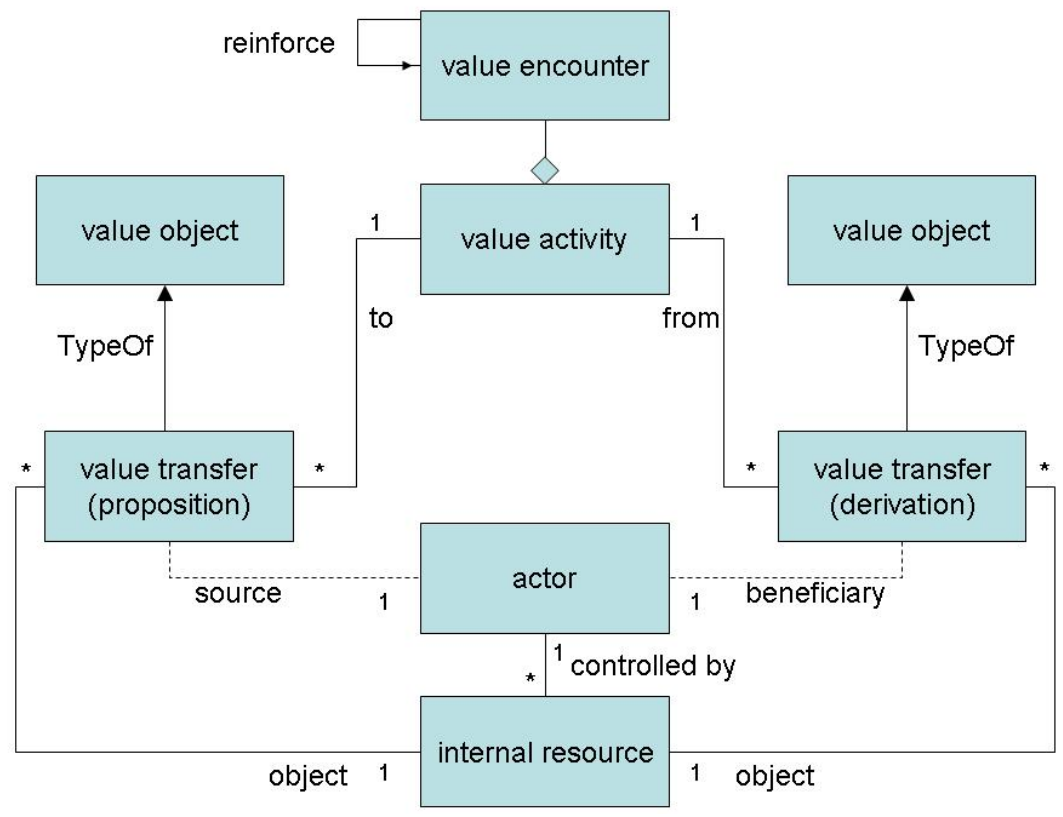

Fig. 6. Value encounter ontology (as a UML class diagram - the dotted lines represent derived relationships) 
The value encounter ontology (Fig. 6) is intended to be a generalization of the e3-value value ontology. Value activities within value encounters get input from value propositions and provide output to value derivations - both are value transfers in e3-value terminology. A value proposition says what the actor brings in (in terms of "resourcing" [16]). A value derivation says what the actor gets out of the value encounter. These connections are viewed as instantiations of a value object, e.g. "negotiation service". The value encounter ontology is a generalization of e3-value: a value encounter can involve more than two actors, whereas a value exchange in e3-value includes only two. The generalization also makes it possible to distinguish between value propositions and value derivations. A value derivation type corresponds to what [15] calls a need, that is, a requested service and a value proposition type to a provided service. A value encounter is an aggregation of value activities. By default (as in the examples in section 4), the value encounter contains one holistic value activity not explicitly rendered in the diagram.

The question what exactly is brought in by an actor, that is, the question of resourcing, is not that simple, as there are many possible business model types and the modeling should not be restricted or biased to a particular kind only. In fact, we can distinguish a whole spectrum of business model types ranging from a typical G-D kind of exchange on the one hand to an advanced S-D kind of value co-creation at the other. Resourcing can be in the form of a good or product that is sold by the Provider, acquired by the Customer, and used internally in some value adding process. In such a case, the value encounter is almost reduced to an object exchange. We say "almost", as even in this case, the encounter involves a service contact between the actors in which secondary values and benefits do play a role. In the case of face-to-face meetings, there is always a social aspect. Somewhere at the middle of the spectrum, resourcing takes the form of services (economically, these are resources as well, cf. $[30,20])$. An example is the arrangement service in Fig. 3 or the after-sales service provided by the Equipment Provider. Such a service draws on internal resources but it is not the internal resource itself. The service can be used within the value encounter (a meeting being organized) or be consumed by some other actor (the patient taking benefit from the advice and improving his health). At the other (S-D) side of the spectrum, the actors provide access to their internal resources - e.g., their knowledge, and these resources are explored by collaborative value activities within the value encounter in order to create something of value. Whether there is indeed a shift from G-D logic to S-D logic remains an empirical question [5], as is the question of the benefits and costs of such a shift.

\section{Discussion}

According to a recent paper by Jim Spohrer and colleagues [Sp08], "formalizing the notion of value-cocreation interactions and further developing the types of value propositions is a challenge for service science". This paper takes up the challenge and has introduced and formalized the notion of value encounter as an extension to current value modeling approaches. It encourages a service-dominant logic view of value networks where value is not viewed as exchanged but as created when different actors come together each bringing in their resources in order to create something of value to 
all. However, it does not exclude G-D based models or hybrid forms. A value encounter model can be subject to various kinds of analysis in order to support strategic management and business redesign [We07]. These, in turn, can be a starting-point for IS design. In a co-design approach, IS design and value encounter modeling can be pursued in parallel [10]. The use of IT may enable innovative extensions of existing value encounters or generate completely new ones.

The introduction of the notion of value encounters draws attention to something not considered yet in value modeling, as far as we know, that is, the relevance of the value exchange context. A value encounter is explicates the context. Sometimes value exchanges can only be realized in the right context, for example, a certain governmental regime. The contribution of this regime is like a catalyst in chemical reactions: it does not participate actively, but without it, the reaction would not take place. The relevance of context has been recognized in economics before, in particular in the theory of country-specific resources (CSRs) and clusters [5]. These theories go back to the work of the early trade theorists who focused their analyses on basic factor inputs such as land, labour and capital. Attention was also paid to the role of geographic location as a country-specific resource. More recent work has broadened the discussion of CSRs to include not only inherited resources but also those that are created by a country. In all these cases, the resource in question is a product of investments made over a long period of time in any given country [11]. Examples are the education system, technological and organizational capabilities, communications and marketing infrastructures, labour productivity and research facilities. Clusters share many characteristics of networks but are differentiated by co-location and active efficiencies. The notion of value encounter allows us to model a geographical unit or cluster not so much as a resource but as a space in which resources are put on the table in order to co-create value. This is relevant to business modeling and strategy analysis. In traditional value modeling, the actors are located in an abstract space. Why a certain value network does grow and prosper in one environment and not in another, remains unexplained. It makes sense to view strategy design as an attempt either to develop completely new value encounters (which typically needs a long line of investment) or to build on and extend already existing value encounters. In the course of time, these value encounters grow and adapt and as such they represent a long history of economic as well as social investments. Such an approach is not only interesting in view of physical environments but also of virtual environments. For example, a social network site as Facebook facilitates value encounters on which companies can capitalize in order to build new business models [31]. The notion of value encounter is a starting-point for developing this way of thinking, but many questions are still open. For instance, how do we delineate and relate contexts? Can we use the reinforcement relationship introduced above for that purpose?

\section{References}

[1] Alter, S.: Service system fundamentals: Work system, value chain, and life cycle. IBM Systems Journal 47/1, 71-86 (2008)

[2] Allee, V.: A Value Network Approach for Modeling and Measuring Intangibles. White paper presented at Transparent Enterprise, Madrid (November 2002) 
[3] Andersson, B., Bergholtz, M., Edirisuriya, A., Ilayperuma, T., Johannesson, P., Gordijn, J., Grégoire, B., Schmitt, M., Dubois, E., Abels, S., Hahn, A., Wangler, B., Weigand, H.: Towards a Reference Ontology for Business Models. In: Embley, D.W., Olivé, A., Ram, S. (eds.) ER 2006. LNCS, vol. 4215, pp. 482-496. Springer, Heidelberg (2006)

[4] Andersson, B., Johannesson, P., Bergholtz, M.: Purpose Driven Value Model Design. In: Proc. CAiSE workshop BUSITAL 2009, CEUR (2009)

[5] Arnould, E.J.: Service-dominant logic and resource theory. J. of the Academy of Marketing Science 36, 21-24 (2008)

[6] Barney, J.: Firm resources and sustained competitive advantage. Journal of Management 17(1), 99-120 (1991)

[7] Blecker, T., Neumann, R.: Interorganizational knowledge management- Some perspectives for knowledge oriented strategic management in virtual organizations. In: Malhotra, Y. (ed.) Knowledge management and virtual organizations, pp. 63-83. Idea Group Publishing, Hershey (2000)

[8] Geerts, G., McCarthy, W.E.: An Accounting Object Infrastructure For Knowledge-Based Enterprise Models. IEEE Int. Systems \& Their Applications, 89-94 (1999)

[9] Gordijn, J., Akkermans, J.M., van Vliet, J.C.: Business modeling is not process modeling. In: Mayr, H.C., Liddle, S.W., Thalheim, B. (eds.) ER Workshops 2000. LNCS, vol. 1921, p. 40. Springer, Heidelberg (2000)

[10] Goldkuhl, G.: Action and media in interorganizational interaction. Comm. ACM 49(5), 53-57 (2006)

[11] Gray, H.P.: Macroeconomic theories of foreign direct investment: An assessment. In: Rugman, A.M. (ed.) New Theories of the Multinational Enterprise, pp. 172-195. CroomHelm, London (1982)

[12] Grönroos, C.: Service Logic Revisited: Who Creates Value? And Who Co-Creates? European Management Review 20(4), 298-314 (2008)

[13] Henkel, M., Johannesson, P., Perjons, E., Zdravkovic, J.: Value and Goal Driven Design of E-Services. In: Proc. of the IEEE Int. Conference on E-Business Engineering (Icebe 2007). IEEE Computer Society, Washington (2007)

[14] Hruby, P.: Model-Driven Design of Software Applications with Business Patterns. Springer, Heidelberg (2006)

[15] de Kinderen, S., Gordijn, J.: E3service: A model-based approach for generating needsdriven e-service bundles in a networked enterprise. In: Proceedings of 16th European Conference on Information Systems (2008)

[16] Koka, B.R., Prescott, J.E.: Strategic alliances as social capital: a multidimensional view. Strateg. Manage. Journal 23, 795-816 (2002)

[17] Lusch, R.F., Vargo, S., Wessels, G.: Toward a conceptual foundation for service science: contributions from service-dominant logic. IBM Systems J. 47(1), 5-14 (2008)

[18] McCarthy, W.E.: The REA Accounting Model: A Generalized Framework for Accounting Systems in a Shared Data Environment. The Accounting Review (1982)

[19] Norman, R., Ramirez, R.: From value chain to value constellation: Designing interactive strategy. Harvard Business Review, 65-77 (July-August 1993)

[20] OASIS. Reference Model for Service Oriented Architecture 1.0 (2006), http: / / www. oasis-open.org/committees/download.php/19679/ soa-rm-c.s.pdf

[21] Osterwalder, A.: The Business Model Ontology, Ph.D. thesis (2004), HEC Lausanne, http: / / www. hec.unil.ch/aosterwa/ (last accessed 007-07-01)

[22] Prahalad, C.K., Krishnan, M.S.: The New Age of Innovation: Driving Cocreated Value Through Global Networks. McGraw Hill, New York (2008) 
[23] Spohrer, J., Anderson, L., Pass, N., Ager, T.: Service-science and service-dominant logic. Otaga Forum 2 (2008), http: / /marketing.otago.ac.nz/events/OtagoForum/

[24] Treacy, M., Wiersema, F.: The Discipline of Market Leaders: Choose Your Customers, Narrow Your Focus, Dominate Your Market. Addison-Wesley, Reading (1995)

[25] Tsai, W., Ghosha, S.: Social Capital and Value Creation: The Role of Intrafirm Networks. The Academy of Management Journal 41(4), 464-476 (1998)

[26] UN/CEFACT Modelling Methodology (UMM) User Guide (2003), http: / / www. unece.org/cefact/umm/UMM_userguide_220606.pdf (2008-02-19)

[27] Vargo, S.L., Lusch, R.F.: Evolving To a New Dominant Logic for Marketing. Journal of Marketing 68, 1-17 (2004)

[28] Weigand, H., Johannesson, P., Andersson, B., Bergholtz, M., Edirisuriya, A., Ilayperuma, T.: On the Notion of Value Object. In: Dubois, E., Pohl, K. (eds.) CAiSE 2006. LNCS, vol. 4001, pp. 321-335. Springer, Heidelberg (2006)

[29] Weigand, H., et al.: Strategic Analysis Using Value Modeling-The c3-Value Approach. In: Proc. HICSS 2007, p. 175 (2007)

[30] Weigand, H., Johannesson, P., Andersson, B.: Bergholtz Value-based Service Modeling and Design: Toward a Unified View of Services. In: Proc. CAiSE 2009, pp. 410-424. Springer, Heidelberg (2009)

[31] Weigand, H.: Value Modeling for the Pragmatic Web - the Case of Social Advertising. In: Proc. I-Semantics, Graz, Austria (September 2009) 